Right heart catheterization confirmed PAH with Mean PAP $58 \mathrm{mmHg}$, LVEDP $8 \mathrm{mmHg}$, PCWP 15mmHg

A diagnosis of Mixed Connective Tissue Disease (MCTD) was made, associated with $\mathrm{PAH}$ and pericardial effusion.

He was started on Ambrisentan and Tadalafil for $\mathrm{PAH}$. Hydroxychloroquine and Mycophenolate Mofetil were also added in view of the PAH being associated with CTD. The additional pericardial effusion confers a poor prognosis.

Conclusion: Association of Spondyloarthritides and Connective Tissue Disease is rare. There are very few case reports of their chance association, especially MCTD ${ }^{2}$. Our patient had been exposed to Sulphasalazine, Infliximab, Adalimumab and Isoniazid, all with a potential to induce an auto immune CTD. MCTD features have persisted despite drug withdrawal. This case may suggest routinely checking for ANA in SpA patients prior to initiating anti TNF drugs.

References:

[1] Brandt J, Maier T, Rudwaleit M et al. Co-occurrence of spondyloarthropathy and connective tissue disease: Development of Sjögren's syndrome and mixed connective tissue disease (MCTD) in a patient with ankylosing spondylitis. Clinical and experimental rheumatology. 2002;20:80-4.

[2] Lee JK, Jung SS, Kim TH, Jun JB, Yoo DH, Kim SY. Coexistence of ankylosing spondylitis and mixed connective tissue disease in a single patient. Clin Exp Rheumatol. 1999;17:263.

Disclosure of Interests: None declared

DOI: 10.1136/annrheumdis-2020-eular.3454

\section{AB1275 HYDROCEPHALUS IN AUTOIMMUNE DISEASES: A SERIES OF CHALLENGING CASES}

\section{N. El Ghobashy ${ }^{1}{ }^{1}$ Cairo University, Cairo, Egypt}

Background: Hydrocephalus can be a rare neurological manifestation but lethal complication of various SAIDs, including systemic lupus erythematosus (SLE), rheumatoid arthritis (RA), sarcoidosis, and primary vasculitis. The commonly used medical management programs based on the etiology of hydrocephalus are anti-inflammatory or anti infectious therapies, while surgical management such as ventriculoperitoneal shunts is effective most of the time (Wei Jetal.,2019). Objectives: To analyze the diagnosis and managment of hydrocephalus associated with autoimmune diseases

Methods: A retrospective case series study was conducted at Rheumatology department.Cairo university. Files were retrieved from the hospital archives by screening records from Jan 2014to Jan2019. Medical records were screened for data regarding the clinical manifestation and outcomeof hydrocephalus associated with autoimmune disease.

Results: Case (1)Male patient 28 yrs old diagnosed a systemic lupus erythematosus The patient was controlled on low dose steroid and azathioprine. In 2019: the patient presented with headache and blurring of vision. Fundus examination showed grade 2 to 3 papilledema. MRI brain showed: Non obustrcutive hydrocephalus. MRA \& MRV: normal laboratory investigation was done and showed consumed c3 \& c4. ESR: $35 \mathrm{~mm} /$ hour. $\mathrm{Hb}: 12.3 \mathrm{~g} / \mathrm{dl}$. WBC:6.38 cells $/ \mathrm{cm} 3$. normal liver and kidney function. Neurosurgery consultation was done and recommended urgent ventriculo -peritoneal shunt. follow up fundus showed improvement of papilledema. The patient was discharged on steroids $30 \mathrm{mg}$ and mycophenolate mofetyl: 2gram with improvement of his condition.Case (2)Female patient $22 \mathrm{yrs}$ old diagnosed as systemic lupus erythematosus onset 2010. In 2018 she started to develop quadriparesis started in left side followed by Right side associated with attacks of Tonic colonic convulsions. MRI brain showed: Marked communicating hydrocephalus with markedly reduced cerebral hemisphere white matter. MRV \& MRA: normal. Her laboratory investigation showed ESR: $49 \mathrm{~mm} / \mathrm{h}$. HB: $10.3 \mathrm{mg} / \mathrm{dl}$, WBC: $5.9 \mathrm{cells} / \mathrm{mm} 3$. Normal platelet count. normal liver \& kidney function. Normal c3 \& c4. neurosurgery consultation was done. Urgent ventriculoperitoneal shunt was done with improvement of her condition. The patient was discharged on solupred $20 \mathrm{mg}$ along with azathioprine.

Conclusion: VPS along with medical treatment with steroids and immunosuppresion represent an effective treatment protocol.

References:

[1] Wei J, Yin H, Wang L, Cui L, Wang R. Systemic autoimmune diseases complicated with hydrocephalus: pathogenesis and management. Neurosurg Rev. 2019 Jun;42(2):255-261.

[2] Wei J, Yin H, Wang L, Cui L, Wang R. Systemic autoimmune diseases complicated with hydrocephalus: pathogenesis and management. Neurosurg Rev. 2019 Jun;42(2):255-261.

[3] Tang SC, Lee CF, Lee CW, Jeng JS. Systemic lupus erythematosus flare up manifestations as cerebral and subarachnoid hemorrhage. Lupus 2011; 20: 1211-13

[4] Kitching GB, Thompson JR, Hasso AN, Hirst AE. Angiographic demonstration of lupus cerebral phlebitis with communicating hydrocephalus. Neuroradiology 1977; 14: 59-63.

[5] Mortifee PRS, Bebb RA, Stein H. Communicating hydrocephalus in systemic lupus erythematosus with antiphospholipid antibody syndrome. J Rheumatol 1992; 19: 1299-302.
[6] Honda K, Matsumoto M, Kaneko T, KAmei I, Tatsumi H, Murai N, et al. Linear deposition of immunoglobulins and complement components on the dura in normal pressure hydrocephalus complicating systemic lupus erythematosus. J Clin Neurosci 2004; 11: 561-63.

[7] Koga H, Ooch IN, Osato S, Ishida I, Hirakata H, Okuda S, Fujishima M (1994) Case report: Wegener's granulomatosis accompanied by communicating hydrocephalus. Am J Med Sci 307:278-281

[8] Bertken RD, Cooper VR (1997) Wegener granulomatosis causingsellarmass, hydrocephalus, andglobalpituitaryfailure.WestJMed 1997; 167:44-47

[9] Scarrow AM, Segal R, Medsger TAJ, Wasko MC (1998) Communicating hydrocephalus secondary to diffuse meningeal spread of Wegener's granulomatosis: case report and literature review. Neurosurgery 1998;43:1470-1473

Disclosure of Interests: None declared

DOI: 10.1136/annrheumdis-2020-eular.6465

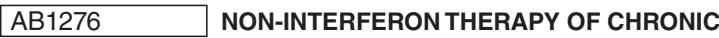 HEPATITIS C IN A PATIENT WITH SYSTEMIC LUPUS ERYTHEMATOSUS AND SECONDARY SJÖGREN SYNDROME - CASE REPORT}

I. Menshikova ${ }^{1}$, Y. Pak ${ }^{2}$, A. Rybaulina ${ }^{3} .{ }^{1}$ I.M. Sechenov First Moscow State Medical University (Sechenov University), Rheumatology Department of Clinical Hospital \#1, Moscow, Russian Federation; ${ }^{2}$ I.M. Sechenov First Moscow State Medical University (Sechenov University), Rheumatology department of University Clinical Hospital \#1, Moscow, Russian Federation 3.M. Sechenov First Moscow State Medical University (Sechenov University), Faculty Therapy Department, Moscow, Russian Federation

Background: Hepatitis $\mathrm{C}$ virus infection is one of the most significant public health problems in the world. To date, the problem of selection of therapy is very relevant for patients with autoimmune diseases and chronic hepatitis $C$ [1] Patients with systemic lupus erythematosus (SLE) are forced to take different doses of steroids, often in combination with immunosuppressants (mycophenolate mofetil, azathioprine, etc.) even in the case of long-term remission. Such therapy for many years can contribute to the reactivation of hepatitis $\mathrm{C}$.

Objectives: To describe a clinical case of the effectiveness of the combined use of interferon-free therapy and therapy of steroids in a patient with SLE, second ary Sjogren syndrome and chronic hepatitis $\mathrm{C}$.

Methods: 56 years-old woman was admitted to the rheumatology department of Clinical Hospital No. 1 in December 2018 with the debut of SLE: photosensitivity, aphthous stomatitis, arthritis, pleurisy, sicca syndrome, leukopenia, ANA 1: 2560, antibodies to dsDNA $55.95 \mathrm{lU} / \mathrm{ml}$, positive antiSS-A (Ro). At the same time, it became known that she was infected with hepatitis $C$ virus in 1985 presumably. At the time of hospitalization, anti-HCV was positive, the virus genotype was $1 \mathrm{~b}$, the activity of the process was low (HCV RNA 6.6×10 4 , AST 33U/L and ALT 25U/L). The patient was prescribed corticosteroids (methylprednisolone $16 \mathrm{mg} /$ day) and hydroxychloroquine $400 \mathrm{mg} /$ day In January 2019, after gastroenterologist, hematologist and infectious disease specialist advise, it was decided to conduct the patient a specific interferon-free antiviral therapy for chronic hepatitis C (a 24-week course with asunaprevir and daclatasvir) given the potential long-term glucocorticoid therapy, with the prospect of treating the patient with cytotoxic drugs, and the possibility of reactivation of chronic hepatitis $C$ amid of immunosuppressive therapy for SLE and Sjogren syndrome.

Results: Low-disease activity of SLE was achieved in a month, and after 24-week course of antiviral therapy, there was no increase in SLE activity, and positive laboratory and clinical dynamics were noted.

Conclusion: Thus, the use of interferon-free therapy of chronic hepatitis $C$ in patients with systemic lupus erythematosus and secondary Sjogren syndrome shows possible ways to safe treatment of this disease in patients with diffuse connective tissue diseases.

\section{References:}

[1] Xiaobo Zhu, Mingqi Wang, Mei Liu, Xinghao Yu \& Peng Huang. Efficacy and safety of direct-acting antivirals for treatment-naive patients with genotype 1 hepatitis C virus infection. Per Med. October 2019. 16 (5): 421 doi: 10.2217/ pme-2018-0121.

Acknowledgments: Supported by the "Russian Academic Excellence Project 5-100"

Disclosure of Interests: None declared

DOI: 10.1136/annrheumdis-2020-eular.6051

\section{AB1277 \\ AUTOANTIBODIES IN NLRP3-ASSOCIATED AUTOINFLAMMATORY DISEASE: A CASE REPORT AND LITERATURE REVIEW}

L. Zhang ${ }^{1}$, Y. Sun ${ }^{2}$, Y. $\mathrm{Li}^{1}$, W. Yu ${ }^{1}$, Y. Wang ${ }^{1}$, D. Wu ${ }^{1}$, W. Zhang ${ }^{1}$, M. Shen ${ }^{1}$, R. Wang ${ }^{2} .{ }^{1}$ Peking Union Medical College, Beijing, China; ${ }^{2}$ School of Basic Medicine Peking Union Medical College, Beijing, China 